\title{
Early trifecta valve failure: Warning shot or unfair scrutiny?
}

\author{
Robbin G. Cohen, MD, MMM
}

From the Department of Surgery, Keck/USC School of Medicine, Los Angeles, Calif.

Disclosures: Author has a teaching agreement with St Jude Medical and serves on the Structural Heart Advisory Board for Medtronic, Inc.

Received for publication June 14, 2017; accepted for publication June 14, 2017; available ahead of print July 8 , 2017.

Address for reprints: Robbin G. Cohen, MD, MMM, 1520 San Pablo St, \#4300, Los Angeles, CA 90033 (E-mail: rcohen@usc.edu).

J Thorac Cardiovasc Surg 2017;154:1241-2

$0022-5223 / \$ 36.00$

Copyright (C) 2017 by The American Association for Thoracic Surgery

http://dx.doi.org/10.1016/j.jtcvs.2017.06.033

Early structural valve degeneration (SVD) is a rare and sporadic complication of all brands of aortic bioprostheses, but an unexpected outbreak of early failures sounds alarms throughout the cardiac surgical community like an exotic infectious disease with epidemic potential. Surgeon users of the culprit valve may consider abandoning its use, given their accountability for their bioprosthetic choices and results in an era of increasing pressure to refer patients for transcatheter aortic valve replacement in lieu of surgery. The industry response ranges from denial and rationalization to an intensive investigation into all aspects of the suspect bioprosthesis, including its history, design, manufacturing process, implantation technique, anticoagulation strategies, and mode of failure. This was the case in 2012, when a transient increase in early failures of the Medtronic Mosaic aortic bioprosthesis led to intense scrutiny into all of these factors. Although no "smoking gun" was uncovered, cautions were raised and new insights gained regarding the potential hazards of "oversizing" when trying to insert the largest bioprosthetic valve possible. ${ }^{1}$

Kalra and colleagues report 8 early Trifecta valve failures during a 5-year period, encountered in a tertiary referral center with extensive experience with Trifecta. ${ }^{2}$ Why this series is considered a "cluster" is not clear. Furthermore, 2 of the patients were not operated initially at their center, which nullifies any possibility of determining a valid denominator when attempting to calculate a valve failure rate. The previously published rate of freedom from reoperation from SVD for Trifecta at 6 years is $97.3 \%$, which is felt to be comparable with other frequently used bioprostheses. ${ }^{3}$

Because early bioprosthetic failures usually are rare and anecdotal, we don't know that much about them. Their causes could be related to patient factors, valve size and design, surgical technique, anticoagulation strategies, or a combination of the above. Most early bioprosthetic failures are the result of subannular pannus leading to prosthetic aortic dysfunction. ${ }^{4}$ Subannular pannus was found in most of the explanted Trifecta valves in this report, raising the possibility of early leaflet thrombosis as recently reported in both surgical aortic valve replacement and transcatheter

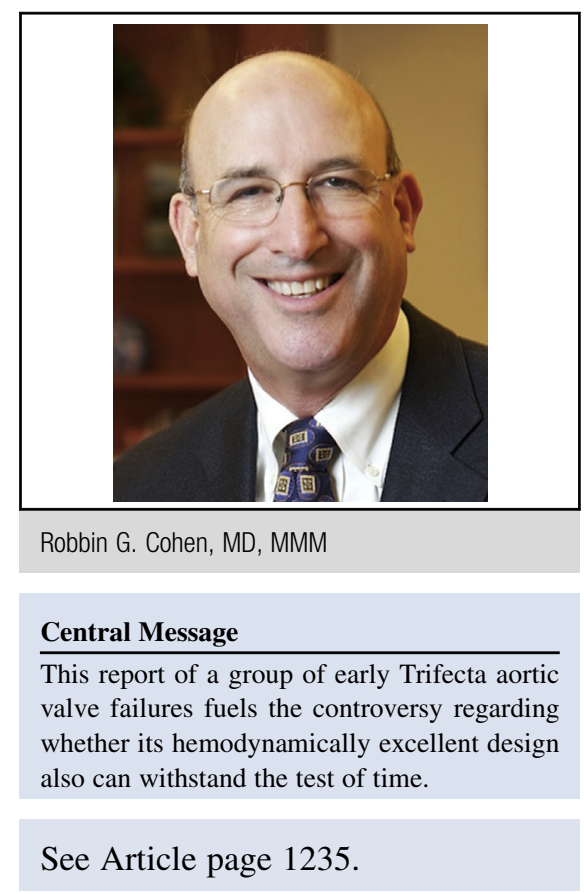

aortic valve replacement valves. ${ }^{5}$ Unlike surgeons in this report, this has prompted many to give postoperative warfarin to patients with bioprosthetic valves for 3 to 6 months. There was also leaflet calcification surrounding the stent posts contributing to SVD in this series of valve failures, which was unexpected, given Trifecta's anticalcification treatment. Hopefully, these early failures are not reminiscent of Trifecta's design cousins, the Ionescu Shiley and Mitroflow valves, which were associated with excellent hemodynamics but inferior durability. ${ }^{6,7}$

Although the authors have reignited the flames of surgeon scrutiny regarding the durability of the Trifecta valve, early failure rates still seem to be reasonable. Regarding long-term durability, only time will tell whether Trifecta's purported structural improvements will make it superior to its predecessors of similar design and comparable with more traditional time-tested stented bioprostheses. For that, the clock seems to be ticking pretty slowly.

\section{References}

1. Cleveland JD, Bowdish ME, Eberhardt CE, Mack WJ, Crabtree JA, Vassiliades TA, et al. Evaluation of hemodynamic performance of aortic valve bioprostheses in a model of oversizing. Ann Thorac Surg. 2017;103:1866-76.

2. Kalra A, Rehman H, Ramchandani M, Barker CM, Lawrie GM, Reul RM, et al Early Trifecta valve failure-report of a cluster of cases from a tertiary care referral center. J Thorac Cardiovasc Surg. 2017;154:1235-40.

3. Goldman S, Cheung A, Bavaria JE, Petracek MR, Groh MA, Schaff HV, et al Midterm, multicenter clinical and hemodynamic results for the Trifecta aortic pericardial valve. J Thorac Cardiovasc Surg. 2017;153:561-9. 
4. Han K, Yang DH, Shin SY, Kim N, Kang JW, Kim DH, et al. Subprosthetic pannus after aortic valve replacement surgery: cardiac CT findings and clinical features. Radiology. 2015;276:724-31.

5. Makkar RR, Fontana G, Jilaihawi H, Chakravarty T, Kofoed KF, de Backer O, et al. Possible subclinical thrombosis in bioprosthetic aortic valves. $N$ Engl $J$ Med. 2015;373:2015-24.
6. Luk A, Cusimano RJ, Butany J. Pathologic evaluation of 28 Mitroflow pericardial valves: a 12-year experience. Ann Thorac Surg. 2015;99: 48-54.

7. Masters RC, Walley VM, Pipe AL, Keon WJ. Long-term experience with the Ionescu-Shiley pericardial valve. Ann Thorac Surg. 1995;60: S288-91. 